\title{
Cropping up Crisis at the Nexus between COVID-19 and AMR in Africa: A Scoping Review and Synthesis of Early Evidence
}

\author{
Girma Gutema ${ }^{1,2, *}$ and Gadissa Homa ${ }^{3}$ \\ 1 Faculty of Health Sciences, Rift Valley University, Adama, Oromia, Ethiopia \\ 2 School of Pharmacy, University of Oslo, Norway \\ 3 Hayat Medical College, Addis Ababa, Oromia, Ethiopia \\ * Correspondence: girmabbaacabsaa@gmail.com
}

\begin{abstract}
Objective: In this study, we aim to synthesize some evidence on the impacts that COVID19 is having on the epidemiology of Antimicrobial Resistance (AMR) in Africa since it was declared global pandemic by WHO in March 2020. Methodology: A scoping review was undertaken by collecting and curating relevant resources from peer-reviewed articles and also from the gray literature. Mixed approaches of extracting data (qualitative and quantitative) were employed in synthesizing evidence, as suggested by Health Evidence Network (HEN). Findings: A model constructed based on the synthesis of early evidences available on the effects of factors linked to COVID-19 in impacting the evolution of AMR in Africa predicted that, in cumulative terms, those factors favoring the evolution of AMR outpace those disfavoring it by no less than three folds. Conclusion: COVID19 is fueling the evolution of AMR almost unhindered in Africa. Due recognition of this crisis, concerted efforts for resource mobilization and global cooperation are needed to tackle it.
\end{abstract}

Keywords: COVID-19 impacts; Antimicrobial resistance; Africa

\section{Introduction}

The viral disease COVID19, caused by a novel variety of severe acute respiratory syndrome corona virus 2 (SARS-COV-2), was first detected in December 2019 in the Chinese central city of Wuhan [1]. From there, it rapidly spread around the world that by the eleventh of March 2020, the World Health Organization had to declare it to be a global pandemic $[2,3]$. Ever since, the pandemic is affecting all the micro and macro-systems constituting the world order as we know it - in a way unprecedented in recent memory so much so that its overall impacts are now thought to carry a tangible opportunity to bring about "the great reset" on the contemporary world order [4]. Indeed, its impacts have already cut across the multiple, interconnected and often interdependent systems in the world - notably in the public health, politics, socioeconomic, environmental and the food chains [5].

Before the arrival of COVID-19 pandemic, no one could imagine that hundreds of thousands of educational institutions around the world completely closing their physical facilities to turn about a billion of their students into homes and internet-based virtual classrooms; governments, companies and corporations across the globe ordering their employees to work from home; national healthcare systems of countries often organized along the "Hobbesian" notion of "nation states" [6] would be rendered functionally incapable - not to say irrelevant - in responding to a disease outbreak with a global scope.

One among the major impacts of the COVID-19 pandemic over the last one year has been the sharp increase in consumption of antibiotics in healthcare settings and also in the community. Such sharp increase in consumption of antibiotics further fuels the challenges posed by Antimicrobial Resistance (AMR) which has hitherto been characterized by the WHO as the greatest threat to global health [7]. 
This COVID-19 pandemic should be a powerful awakening call underpinning a compelling reality that global collaborations would be the most, if not the only, effective strategy to tackle such a global threat today. Data should be collected and analyzed in every country and every continent as to how healthcare responses to COVID-19 pandemic affected AMR epidemiology, Antimicrobial Stewardship (AMS) strategies, programs and systems. Such global collaborations should stimulate and support scientific researches and publications across the globe. Moreover, such studies about the impacts of COVID19 on AMR would even be more imperative in Africa where data on antibiotic resistance patterns are scarce, conditions for transmission of deadly infections are optimal and resources for clinical care are meagre.

The overarching impact of COVID-19 pandemic on AMR in High Income Countries (HIC) has recently been disputed. On the one hand, some researchers argued that given the public health interventions made by governments across the globe in response to the pandemic, like domestic/international travel restrictions, physical distancing measures and enhanced mechanisms of infection prevention and control, among others, COVID-19 will not have significant impact on the evolution of AMR [9]. On the contrary, others argued that regardless of such public health interventions, the impact of the pandemic on AMR is going to be significant [10].

In this paper, we attempted to synthesize early evidence - by integrating findings from peer-reviewed papers and also from the gray literature - on the most likely impacts of COVID-19 pandemic on AMR epidemiology in Africa over the last one year.

\section{Methodology}

\subsection{Search Strategy}

A scoping review method [11] was employed to collate and curate resources in the literature. Mixed approaches of extracting data (qualitative and quantitative), as per the methodological suggestions by Health Evidence Network [12], were used in synthesizing the evidence. Studies included in synthesizing evidence were identified using PubMed/Medline, ScienceDirect databases and also Google scholar. Accordingly, articles published in English language dealing with the interactions between COVID-19 and AMR since the former was declared global pandemic by the WHO in March 2020 were searched and identified. The key terms used in searching the literature were COVID-19 impacts as combined with antimicrobial resistance, antibiotic resistance, antimicrobial use and antibiotic use.

\subsection{Inclusion/Exclusion Criteria}

Studies which separately dealt with either COVID-19 or AMR alone were excluded. Rather, only those which considered both COVID-19 and AMR with either a stated or implicated aim to look into the clinical or pharmacoepidemiologic interactions between the two were included. Ten other studies published before or after the outbreak of the pandemic, including those on the socio-economic impacts of COVID-19, which were found to be relevant in informing the background assumptions and understandings in synthesizing the evidence were also included from references. Fig 1 below shows PRIZMA-ScR flow diagram of literature selection proceedings. 


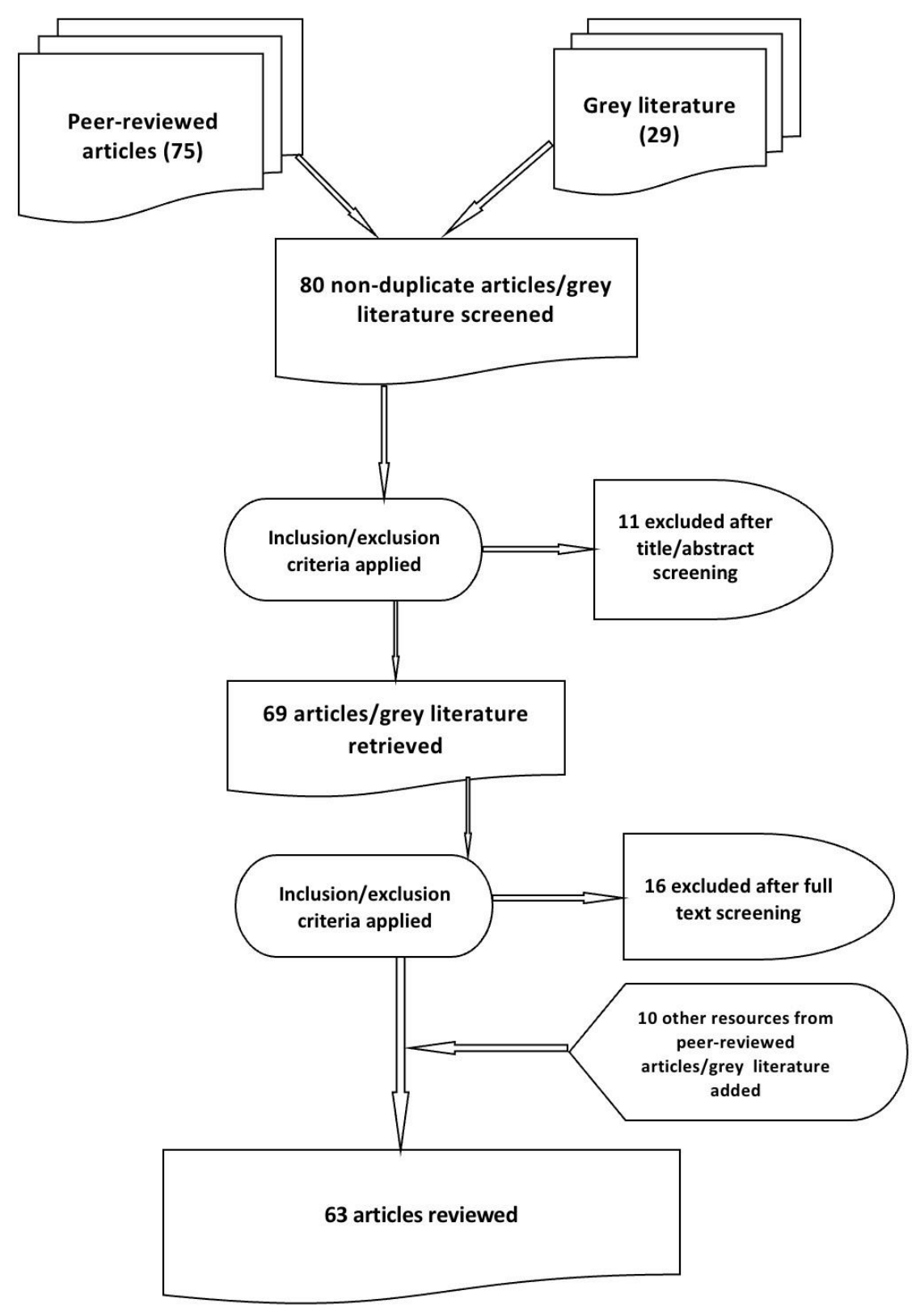

Figure 1. PRIZMA-ScR flow diagram of literature selection.

\section{Synthesis and Interpretations of the Evidence}

In Africa, the first case of COVID-19 was detected in Egypt on the $14^{\text {th }}$ of February 2020 [13] - about a month before WHO declared it a global pandemic - while the last case was detected in Lesotho about three months later [14]. As per the latest data from the African Union's health monitoring portal on COVID-19, Africa CDC, updated by the $9^{\text {th }}$ of April 2021, there are a total of 4.3 million confirmed cases in Africa of which are about 115,000 deaths, 3.9 million recoveries and the rest being active cases [15]. From these, the number of confirmed cases and deaths per 100000 population in Africa by the $9^{\text {th }}$ of April 2021 would therefore be 332 and 9, respectively.

The true picture on the epidemiology of COVID-19 in Africa or elsewhere in the world would emerge only after the end of the pandemic. But at least at this point in time, the above statistics may appear to portray the African continent as "the least affected" albeit erroneously. Notwithstanding these statistics, we argue that the following factors might have contributed in informing the figures in these statistics: 
Under reporting: healthcare systems in most African countries are underdeveloped and hence weak. They lack up to date technological means for accurate health data collection and reporting, struggle with meager resources and hardly favorable workplace environments to capture data in the right quantity and quality.

Demographic factors: the median age of Africa's population is 19.7 years, which makes Africa the youngest continent on the planet. A study showed that the crude fatality rate of COVID-19 patients above the age of 70 years exceeds those of below 20 by about 625 folds [16].

The hygiene hypothesis: the hygiene hypothesis in medicine states that early childhood exposure to particular microorganisms (like the intestinal flora and other helminthics) could protect against allergic diseases by contributing to the development of the body's natural immunity [17]. In a way, this might have had also helped Africa.

Our take on the overarching impacts that COVID-19 is likely having on the epidemiology of AMR in Africa is anchored on a model that we constructed based on the synthesis of early evidences available. Computer-based-simulations of the areas of the geometric figures constructed for the cumulative impacts of factors favoring and disfavoring the evolution of AMR in the model show that the former outpaces the later by no less than 300 percent (see Fig. 2).

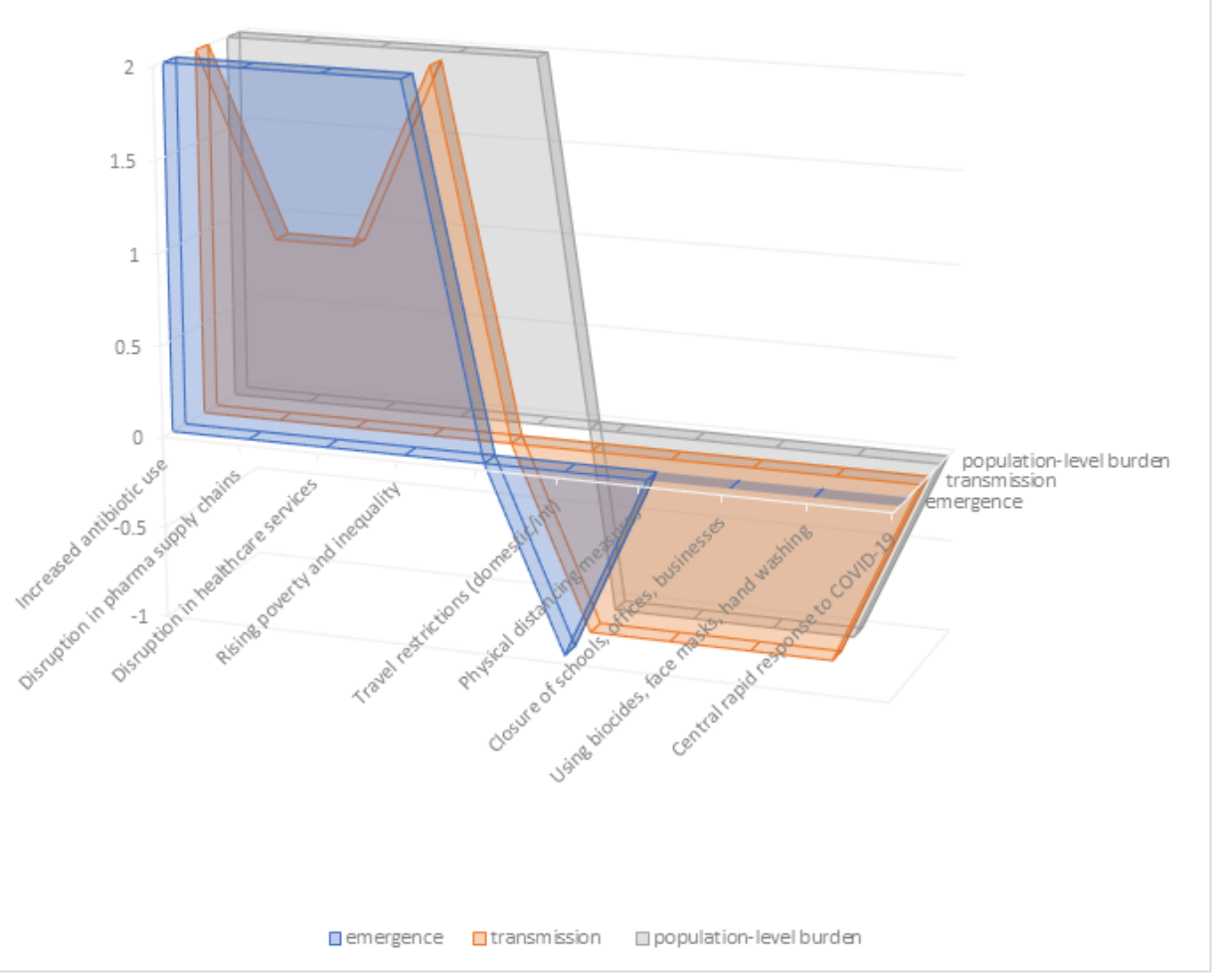

Figure 2. Model constructed based on the opposing interactions that specific factors driven by COVID-19 pandemic - shown here by areas of the geometric figures on the positive side of Y-axis - and those factors driven by the public health responses to COVID-19 pandemic - shown by the area of the geometric figures on the negative side of Y-axis - are having with the three determinants of AMR evolution. Assumptions and designations about the effects of the specific factors on the determinants in constructing the model were: a) no effect $=0, b)$ positive effect (moderate) $=1, c)$ positive effect (strong) $=2, d$ ) negative effect $($ moderate $)=-1, e)$ negative effect (strong) $=-2$.

To put our points in context as to how COVID-19 pandemic is impacting AMR in Africa, we contend that a holistic approach that takes into account the three determinants 
driving the evolution of AMR epidemiology as well as the public health interventions put in place by various countries in Africa is imperative. These three determinants of the evolution of AMR in populations are: 1) emergence of antimicrobial resistant organisms (AROs) 2) transmission of AROs and 3) population-level burden of infections caused by AROs [18].

There could be several factors which interact with these three determinants of AMR, either positively or negatively. For the purpose of presenting some qualitative analyses in this paper, such factors have however been categorized into two major groups: 1) those driven by the outbreak as well as community transmission of COVID-19 and 2) those related to the public health interventions made in response to the COVID-19 pandemic. The interactions that the two categories of factors have with the determinants of AMR evolution are dialectical. Specific factors which can be enlisted under the first category as directly linked to the outbreak and community transmission of the pandemic include increasing antibiotic use, disruption in pharmaceutical supply chains, disruption in access to healthcare services, rising poverty as well as inequality within the population. On the other hand, those factors interacting with the three determinants as related to the public health responses put in place by governments to halt the spread of COVID-19 include travel restrictions (domestic/international), physical distancing measures, closing schools, businesses, government offices, employment of enhanced infection prevention and control measures in healthcare settings as well as in the community and setting up centralized rapid response systems to COVID-19 pandemic. The common measures taken to enhance infection prevention and control include frequent hand washing, using biocidal hand sanitizers, environmental disinfectants and wearing face masks.

To gauge the overall impact of the pandemic on the epidemiology of AMR in Africa, taking a closer look at how specifically these various factors could interact with those determinants - individually or in concert - and examining the overarching outcome of these interactions within the wider context of healthcare and community settings in Africa would be imperative [19]. See Fig 2 for the model constructed based on such interactions. Below, therefore, we base our assumptions in this model to examine such overarching outcome of these interactions.

\subsection{Increasing use of antibiotics}

The rise in the emergence of AMR, secondary to the increasing use of antibiotics after the outbreak of COVID-19, has been of great concern globally [20,21]. Following the outbreak of COVID-19 pandemic in March 2020, sharp rise in antibiotic prescriptions have been documented in different parts of the world [22 - 25]. At the level of specific product, for instance, up to $400 \%$ increase in consumption of azithromycin has been reported during this pandemic season [26]. Such sharp rises in the consumption of antibiotics during this pandemic season are being driven by the prescriptions of antibiotics for empirical treatments, for treatment of health facility acquired infections (HAIs) and also for the treatment of post-COVID-19 complications, particularly during the recovery stage.

\subsubsection{For empirical treatment of COVID-19 and secondary co-infections}

Antibiotics were excessively used as empirical treatment in COVID-19 patients, particularly during the early periods after the outbreak of the pandemic [27]. Such empirical uses of antibiotics for the clinical management of COVID-19 have been in the official treatment protocols put in place in response to the pandemic in most countries in line with WHO's interim guideline for the clinical management of suspected COVID-19 cases [28]. The macrolide, azithromycin, has been rapidly repurposed for empiric treatment of COVID-19 due to its extended antiviral effect [29]. Besides, suspected bacterial or fungal co-infections with the corona virus can also be the major driver of the rising antibiotic consumption during this season of COVID-19 pandemic [30,31]. This bodes well particularly with resource-limited settings in Africa where basic facilities to perform laboratory screening for specific bacterial co-infections are not only hardly available but also testing 
service for COVID-19 are lacking in most healthcare facilities. In Ethiopia, for instance, only 72 facilities provide COVID-19 testing services for a population of about 110 million [32]. But such high consumption of antibiotics for secondary co-infection has also been the case in most parts of the globe. It seems this practice was partly influenced by the earliest and most influential studies like the one from China [33] and also of prior pandemics in history [34] which reported that half of patients who died of COVID-19 and the 1918 "Spanish flu" pandemic had secondary c0-infections.

What is more, the potential synergy between viral and bacterial pathogens in exacerbating infections also appear to be at play in driving decisions to frequently use antibiotics in suspected secondary co-infections as that seem to be supported by pathophysiological evidence. Studies have shown that respiratory viral infections may affect the innate immunity of the respiratory system thereby promoting bacterial proliferation, and also increasing the growth of macrophages due to the increased burden of apoptotic cells [35]. Details on this pathogenesis as driven by such effects on innate immune functions likely leading to synergy between co-infections caused by viral and bacterial pathogens have been discussed elsewhere [36].

\subsubsection{For treatment of health facility acquired infections (HAIs)}

Patients with severe cases of COVID-19 infection acquire HAIs - more often than not - not least because they stay on mechanical ventilators in healthcare facilities for some period of time that it will be very likely that they acquire such infections and hence need antibiotics [37, 38]. The possible shortage of mechanical ventilators in most settings in African might be cited as reason to downplay the role of HAI in boosting antibiotic use. Notwithstanding the paucity of data on the extent of mechanical ventilators available for use in healthcare settings in Africa, such an argument cannot water down the ground reality that HAIs are also key drivers of increasing antibiotic consumption in Africa.

\subsubsection{For treatment of patients in post-COVID-19 complications}

COVID-19 could cause extensive damages to lung tissues and their innate immunity due to a condition driven by the devastating effect of immune dysregulation called cytokine storm [39]. Cytokine storm can be triggered by severe viral infections, like COVID19 , and it may lead to a host of complications thereby leaving recovering patients highly susceptible, including to secondary infections [40]. This, therefore, is also one of the factors driving the increasing use of antibiotics in this season of the pandemic. Here, optimum ground realities for this case - malnourished and immunocompromised patients, high burden of infectious diseases, insufficient infection prevention and control mechanisms, lack of clean water etc - compliment this problem in Africa and therefore further promote the increasing use of antibiotics in this pandemic season [41].

The impacts of increasing antibiotic use on the transmission of AMR could theoretically be arrested by factors related to the public health responses to the pandemic like travel restrictions, physical distancing, closure of schools, businesses, wearing face masks, frequently washing hands and using biocidal hand sanitizers or environmental disinfectants. But in most settings in Africa, such measures might not have been strictly and properly implemented - due to a number of practical limitations - even when officially declared $[42,43]$. This reality, therefore, possibly offsets the intended benefits of those public health interventions in Africa. As a result, it can be argued that COVID-19 pandemic is unhindered in driving the population-level burden of AROs as well in Africa.

\subsection{Disruption of pharmaceutical supply chains}

Most countries in Africa import their essential medicines, including antibiotics, from abroad. For instance, countries like Ethiopia and Sudan import about $80 \%$ and $70 \%$ of all the pharmaceuticals they need, respectively [44, 45]. Given the fact that the outbreak of COVID-19 pandemic brought the global supply chains of goods and services essentially to a standstill, the disruption of the supply chains in the international pharmaceutical 
trade as a result would significantly affect the availability and hence access to antibiotics in most African countries. Such lack of access to antibiotics in situations where the outbreak of the COVID-19 pandemic is further fueling the consumption of antibiotics would bring a knock-on effect on the demands of antibiotics in healthcare settings and also in the community. In fact, this knock-on effect on the demands of antibiotics coupled with cuts in the production lines at pharmaceutical manufacturers due to the outbreak of the pandemic created shortage of medications in the market [46]. This in turn revitalizes the circulation of substandard or counterfeited antibiotics, the illegal supply chains of which had hitherto been established more in Africa [47]. Such increasing use of substandard and counterfeited antibiotics in Africa would therefore further fuel the three determinants which drive the epidemiology of AMR - emergence, transmission and population-level burden of AROs.

In addition, disruption in the supply chains of pharmaceuticals in Africa exacerbates the already dire conditions of AMR by disrupting the continuous supply of regimens to patients hitherto on antimicrobial treatments. Patients whose supply of antimicrobial regimens disrupted due to the pandemic would either discontinue their treatments or else resort to purchasing counterfeited or substandard products from the black market. Whichever way patients would have to respond to the disruption of their regimens, the end result is one and same - treatment failure. Treatment failure due to discontinuation of regimens (that is using suboptimal quantity) and due to the use of counterfeited drug products (that is using suboptimal quality) ultimately leads to the emergence of AMR [48]. The prevailing optimum conditions for its transmission in Africa subsequently enhance the burden of drug resistant infections in the population.

\subsection{Disruption of access to healthcare services}

The other immediate impact of the outbreak of COVID-19 in most parts of the world has been the disruption it caused to the provision of regular clinical and non-clinical services in most healthcare facilities [49]. In most countries, centrally coordinated rapid response systems to COVID-19 were setup following WHO's declaration of the viral outbreak as a global pandemic. This essentially diverted resources, policy attention and administrative actions towards such emergency responses to the pandemic, leaving other clinical and non-clinical services disrupted. For instance, WHO's preliminary analysis on five key essential health service indicators - outpatient consultation, inpatient admission, skilled birth attendance, treatment of confirmed malaria cases and provision of the combination pentavalent vaccine in fourteen African countries - revealed a sharp decline in these services between January and September 2020 compared with the two previous years [50]. The report indicated that during the three months period when wider drops in services were observed (May, June, July), services in the five monitored areas dropped on average by more than $50 \%$ in the fourteen countries, as compared to the same period in 2019. In another study in which the damages caused by such disruptions to healthcare services for HIV/AIDS, tuberculosis and malaria in low-income and middle-income countries were epidemiologically modeled, it was reported that deaths due to the three diseases over the coming five years could increase by up to $10 \%, 20 \%$, and $36 \%$, respectively, as compared to no COVID-19 pandemic scenario [51]. Moreover, the disruption in healthcare services due to the pandemic also disrupted child vaccination programs against bacterial and viral infections like diphtheria, pertussis, polio and measles [52]. The pandemic also negatively affected healthcare seeking behavior of the population not only in Africa [53], but also in other parts of the world [54]. The updated interim guideline of WHO recommends integration of AMS programs with the clinical management of COVID-19 [55], but even in countries with advanced healthcare systems, antimicrobial stewardship programs are reported to have already become "COVID's casualty" [56, 57]. There is no rationale to think of this impact to be otherwise in the very few African countries where scanty stewardship programs had been reported earlier [58, 59,60]. The cumulative outcome of such impacts of the pandemic would be a rise in the burden of 
infectious diseases in the general population which in turn fuels the emergence and spread of AMR in Africa.

\subsection{Rising poverty and inequality}

COVID-19 pandemic and the public health policy interventions to halt the spread of the virus have taken a dramatic toll on the global economy [61]. Sub-Saharan Africa region is said to be one of the hardest-hit by the socio-economic impacts of the pandemic [62]. The outbreak of the pandemic dried up the inflow of remittances, essentially frozen the tourism industry and also foreign direct investment in the sub-Saharan Africa region.

According to an early bird's eye view study conducted by the United Nations Conference on Trade and Development, the Gross Domestic Products (GDP) of countries in Africa could contract by as high as $7.8 \%$ due to the impacts of COVID-19 pandemic [63]. Moreover, total merchandize exports of the countries could decrease by an average of about $17 \%$. Another study - a survey commissioned by the World Bank - on the socioeconomic impacts of COVID-19 in four African countries (Ethiopia, Malawi, Nigeria and Uganda) reported that an estimated 258 million people - accounting for nearly $80 \%$ of the whole populations across the four countries - have lost income due to the pandemic. This study found out that about $20 \%$ to $25 \%$ of households in each of these four countries were unable to purchase essential medicines and food staples due to the devastating economic impacts of COVID-19 pandemic [64].

If we further focus our analytical lens on Ethiopia as a case study to illustrate the impacts that COVID-19 is having in the socioeconomic arena in Africa - particularly in exacerbating poverty and inequality - we find compelling data that warrant some brief reviews, as summarized in the table below.

Table 1. Early evidences on the socioeconomic impacts of COVID-19 in Ethiopia [Data sources: 65, 66].

\section{Key socioeco- nomic parameter \\ Trade \\ Remittances \\ Foreign direct in- vestment (FDI) Value of Ethio- pian currency (Birr)}

Inflation

Fiscal expenditure and revenue

\section{Poverty}

Jobs

\section{Impact of COVID-19 pandemic}

-about 30\% drop in export of goods and services in 2020

-expenditure on fuel import drops by 50\% (from $\$ 2.6$ billion in 2019 to $\$ 1.3$ billion in 2020)

-significant loss at the Ethiopian Air Lines

-up to $15 \%$ drop in remittances (estimated at $\$ 850$ million)

-sharp and sustained decrease in FDI

-the birr could depreciate by up to $17 \%$ in nominal terms against US dollar by the end of 2020

-consumer price index $\geq 20 \%$

-inflation in food price $\geq 30 \%$

-revenue hit hard due to contraction in economy, fall in trade taxes (import, export)

-over 2 million people fall into poverty

\section{Remarks}

-could be exacerbated by instability and conflicts in the country

-estimate in best case scenario

-partly compensated by globally reactivated cargo traffic esp with supplies of PPEs and COVID-19 vaccines

-estimate at the upper limit

-this could be further exacerbated by conflicts and instability in the country

-depreciation of birr could be sharper given global/regional conditions and the external pressure

-by end of 2020

-conservative estimate

-people who depend on handouts for basic survival including food - safety net - could increase by about $70 \%$

-up to $15 \%$ loss of employments or livelihoods ( $\geq 4$ million people by conservative estimate)

-crisis could be exacerbated by displacements due to conflicts

What is more, sharp increase in the use of biocides for the purposes of personal hand sanitization as well as environmental disinfection have been the other important impact 
of the COVID-19 pandemic [67]. Such a sharply rising use of biocides following the outbreak of the pandemic is reshuffling the microbiota [68]. As has been discussed earlier, this has largely been driven by measures taken as part of public health responses to the pandemic in most parts of the world. Biocides are employed to kill or stop the spread of pathogenic microorganisms. These are antiseptics or disinfectants which often act via some biological or chemical mechanisms. The most commonly employed active agents in those widely used biocides - particularly in Africa - include ethyl alcohol (denatured), hydrogen peroxide, sodium hydrochloride, triclosan, chlorhexidine, quaternary ammonium compounds and surfactants, among others [69]. In a recent editorial article published on the Bulletin of the $\mathrm{WHO}$, scientific researches were called for on the short as well as long term impacts of the rising use of biocides on fueling cross-resistance to antimicrobials during this season of the COVID-19 pandemic [20].

Earlier reports established that there exist links between the increasing use of biocides - much like antibiotics - and selective pressure on the development of antimicrobial resistance. For instance, in a review in which the effects of the sublethal concentrations of thirteen biocidal agents on antibiotic resistance in gram-negative bacterial species were evaluated, Kampf documented details on antibiotic tolerance, complete resistance as well as mechanisms of resistance development, including horizontal gene transfer and pumping efflux. Accordingly, various strains of bacteria adapted to benzalkonium chloride were found to be resistant to some commonly used antibiotics like ampicillin, cefotaxime and sulfamethoxazole. Moreover, with the other frequently used biocidal agent chlorhexidine, resistance by multiple strains of gram-negative bacteria against antibiotics like ceftazidime, sulfamethoxazole, tetracycline, cefotaxime and imipenem were reported. The study also documented cross-resistance to antibiotics with some biocidal agents including triclosan and sodium hypochlorite, among others [70].

The increasing use of biocidal agents as triggered by the knock-on effect of the public health responses to the COVID-19 pandemic in Africa or elsewhere in the world would inevitably enhance the quantities of biocidal agents disposed into waste waters, recipient rivers and the wider ecosystem [71, 72]. The disposal of large quantities of such biocidal agents into the natural environment brings about an effect of a sword with double edges - both dangerous - depending on their concentrations within the recipient physical environment.

In the first scenario in which biocidal agents would be detected in the recipient environment in some increasing concentrations but while remaining below the minimum threshold needed to kill or inhibit the growth of bacterial colonies present, they increase selective pressure thereby enhancing the emergence of AMR. On the flip side, if these disinfectants/sanitizers dumped into the recipient environment are detected in quantities above the minimum lethal concentrations, they would likely kill or inhibit the growth of most bacterial species in the environment. This too might not be required as it brings about negative impacts by destroying the useful or/and harmless bacterial species which contribute in keeping the biological balances - the microbiota - within the wider ecosystem [73].

Overall, the increasing use of not only these biocides but also antimicrobials both in healthcare and community settings will certainly increase and further buildup the quantities of these active agents disposed into the environment [71]. It is also likely that the increasing use of disinfectants and sanitizers would continue during this season of COVID-19 pandemic, and even remains so in the post-pandemic era due compelling policy changes on infection prevention and control protocols in healthcare settings as well as in the community. If grabbed wisely, this current threat of the crisis cropping up at the nexus between COVID-19 and AMR can be turned into opportunity to redefine the approach to AMS, including through strengthening diagnostic capacity in Africa [74]. Improved data collection approach that transcends beyond passive surveillance - one which is clinically focused, linking risk factors, microbiology, treatment costs and out comes needs to be designed. Sets of other challenges and opportunities that COVID-19 could offer with regard to AMR are discussed elsewhere [75]. And as it goes, we need 
more of rigorous scientific studies which can shed light on the unfolding crisis at the nexus between COVID-19 and AMR epidemiology in Africa and elsewhere in the world.

\title{
4. Conclusion
}

COVID-19 is fueling the evolution of AMR almost unhindered in Africa. Due recognition of this crisis, concerted efforts for resource mobilization and global cooperation are needed to tackle it. There might be some non-constructive scholarly arguments today including those supported by technological algorisms - that human ingenuity defeats this COVID-19 pandemic and its impacts including on AMR. But such assertions are often anchored on short-sighted assumptions that human minds can do miracles without social, cultural, economic, technological and political cooperation among countries. The crisis which is cropping up at the nexus between COVID-19 and the already brewing crisis of AMR in Africa, and also around the world, can only be tackled through a concerted global cooperation. Cooperation not contradiction between nationalism and globalism is the way out.

\begin{abstract}
Acknowledgments: Dr Mirgissa Kaba from Addis Ababa University's School of Public Health helped us refine our conceptualization of the study and also criticality reviewed the first draft of the manuscript. Seid Ali from the Swiss Tropical and Public Health Institute, University of Basel, Switzerland, reviewed the final manuscript and gave us some invaluable insights. We are grateful to both of them.
\end{abstract}

Funding: No fund received.

Conflicts of Interest: None declared.

Ethical approval: Not required.

\section{References}

1- Chakraborty C, Sharma AR, Sharma G, Bhattacharya M, Lee SS. SARS-CoV-2 causing pneumonia-associated respiratory disorder (COVID-19): diagnostic and proposed therapeutic options. Eur Rev Med Pharmacol Sci. 2020;24(7):4016-4026. doi: 10.26355/eurrev_202004_20871.

2-WHO. Director-General's opening remarks at the media briefing on COVID-19. March 11 2020. WHO Director-General's opening remarks at the media briefing on COVID-19 - 11 March 2020. Accessed 18 February 2021.

3- Cucinotta D, Vanelli M. WHO declares COVID-19 a pandemic. Acta Biomed. 2020;91(1):157-160. doi: 10.23750/abm.v91i1.9397.

4- Umbrello S. Should we reset? a review of Klaus Schwab and Thierry Malleret's 'COVID-19: The Great Reset'. J Value Inquiry 2021. doi: $10.1007 / \mathrm{s} 10790-021-09794-1$

5- Hawkes C. Five steps towards a global reset: Lessons from COVID-19. Global Sustainability. 2020;3:E30. doi:10.1017/sus.2020.24

6- Hardin R. Hobbesian political order. Political theory. 1991;19(2):156-180. doi:10.1177/0090591791019002002

7- WHO. Antibiotic resistance. Antibiotic resistance (who.int). Accessed 19 January 2020.

8- WHO. Managing epidemics: key facts about deadly diseases 2018. managing-epidemics-interactive.pdf (who.int) Accessed 11 January 2021.

9- Collignon P, Beggs JJ. CON: COVID-19 will not result in increased antimicrobial resistance prevalence, JAC. 2020; 2(3). doi: $\underline{10.1093 / j a c a m r / d l a a 051}$

10- Duin DV, Barlow G, Nathwani D. The impact of the COVID-19 pandemic on antimicrobial resistance: a debate, JAC. 2020; 2(3). doi: 10.1093/jacamr/dlaa053

11- Sucharew H, Maurizio Macaluso M. Methods for research evidence synthesis: the scoping review approach. J. Hosp. Med 2019;7;416-418. doi:10.12788/jhm.3248

12- Karlsson LK, Takahash R. Health evidence network synthesis report 50. A resource for developing an evidence synthesis report for policy-making. HEN50-Web.pdf (who.int). Accessed 10 January 2021.

13- Lone SA, Ahmad A. COVID-19 pandemic - an African perspective. Emerg Microbes Infect. 2020;9(1):1300-1308. doi:10.1080/22221751.2020.1775132

14 - Aljazeera news. Lesotho becomes last African country to record coronavirus case. 13 May, 2020.

Lesotho becomes last African country to record coronavirus case | Coronavirus pandemic News | Al Jazeera. Accessed 2 March 2021.

15- Africa CDC. Coronavirus disease 2019 (COVID-19): latest updates on the COVID-19 crisis from Africa CDC. Coronavirus Disease 2019 (COVID-19) - Africa CDC. Accessed 9 April 2021.

16- Undurraga EA, Chowell G, Mizumoto K. COVID-19 case fatality risk by age and gender in a high testing setting in Latin America: Chile, March-August 2020. Infect Dis Poverty 2021;10(1):11. doi: 10.1186/s40249-020-00785-1.

17-Daley D. The evolution of the hygiene hypothesis: the role of early-life exposures to viruses and microbes and their relationship to asthma and allergic diseases. Curr Opin Allergy Clin Immunol. 2014;14(5):390-6. doi: 10.1097/ACI.0000000000000101. 
18- Knight GM, Glover RE, McQuaid CF, Olaru ID, Gallandat K, Leclerc QJ et al. Antimicrobial resistance and COVID-19: intersections and implications. Elife 2021;10:e64139. doi: 10.7554/eLife.64139.

19-Lucien MAB, Canarie MF, Kilgore PE, Jean-Denis G, Fénélon N, Pierre M et al. Antibiotics and antimicrobial resistance in the COVID-19 era: perspective from resource-limited settings. Int J Infect Dis. 2021;104:250-254. doi: 10.1016/j.ijid.2020.12.087.

20- Getahun H, Smith I, Trivedi K, Paulin S, Balkhy HH. Tackling antimicrobial resistance in the COVID-19 pandemic. Bull World Health Organ. 2020;98(7):442-442A. doi: 10.2471/BLT.20.268573.

21- Monnet DL, Harbarth S. Will coronavirus disease (COVID-19) have an impact on antimicrobial resistance?. Euro Surveill. 2020;25(45):2001886. doi:10.2807/1560-7917.ES.2020.25.45.2001886

22- Hsu J. How covid-19 is accelerating the threat of antimicrobial resistance. BMJ. 2020;369:m1983. doi: 10.1136/bmj.m1983.

23- Martin AJ, Shulder S, Dobrzynski D, Quartuccio K, Pillinger KE. Rate of antibiotic use and associated risk factors in COVID-19 hospitalized patients. medRxiv 2020.10.21.20217117; doi: $\underline{10.1101 / 2020.10 .21 .20217117}$

24- Rawson TM, Moore LSP, Zhu N, Ranganathan N, Skolimowska K, Gilchrist M et al. Bacterial and fungal coinfection in individuals with coronavirus: a rapid review to support COVID-19 antimicrobial prescribing. Clin Infect Dis. 2020;71(9):2459-2468. doi: 10.1093/cid/ciaa530.

25- Langford BJ, So M, Raybardhan S, Leung V, Soucy JPR, Westwood D et al. Antibiotic prescribing in patients with COVID-19: rapid review and meta-analysis. Clin Microbiol Infect. 2021;27(4):520-531. doi:10.1016/j.cmi.2020.12.018

26- Gonzalez-Zorn B. Antibiotic use in the COVID-19 crisis in Spain. Clin Microbiol Infect. 2020;27(4):646-647. doi:10.1016/j.cmi.2020.09.055

27- Beović B, Doušak M, Ferreira-Coimbra J, Nadrah K, Rubulotta F, Belliato M et al. Antibiotic use in patients with COVID-19: a 'snapshot' Infectious Diseases International Research Initiative (ID-IRI) survey. J Antimicrob Chemother. 2020;75(11):3386-3390. doi: $10.1093 /$ jac/dkaa326.

28- WHO. Clinical management of severe acute respiratory infection (SARI) when COVID-19 disease is suspected; interim guidance, 13 March 2020. Microsoft Word - 20200112 Clinical Management of Novel CoV Final.docx (who.int) Accessed 20 March 2021.

29- Gyselinck I, Janssens W, Verhamme P, Vos R. Rationale for azithromycin in COVID-19: an overview of existing evidence. BMJ Open Respiratory Research 2021;8:e000806. doi: 10.1136/bmjresp-2020-000806

30-Vaughn VM, Gandhi T, Petty LA, Patel PK, Prescott HC, Malani AN et al. Empiric antibacterial therapy and community-onset bacterial co-infection in patients hospitalized with covid-19: a multi-hospital cohort study. Clin Infect Dis. 2020:ciaa1239. doi: 10.1093/cid/ciaa1239.

31- Nori P, Cowman K, Chen V, Bartash R, Szymczak W, Madaline T et al. Bacterial and fungal coinfections in COVID-19 patients hospitalized during the New York City pandemic surge. Infect Control Hosp Epidemiol. 2021;42(1):84-88. doi:10.1017/ice.2020.368

32-Mulu A, Bekele A, Abdissa A, Balcha TT, Habtamu M, Mihret A et al. The challenges of COVID-19 testing in Africa: the Ethiopian experience. Pan Afr Med J. 2021;38:6. doi: 10.11604/pamj.2021.38.6.26902.

33- Zhou F, Yu T, Du R, Fan G, Liu Y, Liu Z et al. Clinical course and risk factors for mortality of adult inpatients with COVID-19 in Wuhan, China: a retrospective cohort study. Lancet. 2020;395(10229):1054-1062. doi: 10.1016/S0140-6736(20)30566-3.

34- Morens DM, Taubenberger JK, Fauci AS. Predominant role of bacterial pneumonia as a cause of death in pandemic influenza: implications for pandemic influenza preparedness. J Infect Dis. 2008;198(7):962-970. doi:10.1086/591708

35- Morgan DJ, Casulli J, Chew C, Connolly E, Lui S, Brand OJ et al. Innate immune cell suppression and the link with secondary lung bacterial pneumonia. Front Immunol. 2018;9:2943. doi:10.3389/fimmu.2018.02943

36-Hanada S, Pirzadeh M, Carver KY, Deng JC. Respiratory viral infection-induced microbiome alterations and secondary bacterial pneumonia. Front Immunol. 2018;9:2640. doi: 10.3389/fimmu.2018.02640.

37- Sharifipour E, Shams S, Esmkhani M, Khodadadi J, Fotouhi-Ardakani R, Koohpaei A et al. Evaluation of bacterial co-infections of the respiratory tract in COVID-19 patients admitted to ICU. BMC Infect Dis. 2020;20(1):646. doi: 10.1186/s12879-020-05374-z.

38- Wang J, Zheng X, Chen J. Clinical progression and outcomes of 260 patients with severe COVID-19: an observational study. Sci Rep. 2021;11: 3166. doi: 10.1038/s41598-021-82943-5

39- Shi Y, Wang Y, Shao C, Huang J, Gan J, Huang X et al. COVID-19 infection: the perspectives on immune responses. Cell Death Differ. 2020;27(5):1451-1454. doi: 10.1038/s41418-020-0530-3.

40- Fajgenbaum DC, June CH. Cytokine Storm. N Engl J Med. 2020;383(23):2255-2273. doi: 10.1056/NEJMra2026131.

41- Patel E, Moodley A. The straw that might break the camel's back: exploring the link between COVID-19 and antibiotic resistance in low- and middle-income countries. ILRI, 2020. The straw that might break the camel's back: exploring the link between COVID-19 and antibiotic resistance in low- and middle-income countries I International Livestock Research Institute (ilri.org). Accessed 15 February 2021.

42- Kaseje N. Why Sub-Saharan Africa needs a unique response to COVID-19. World Economic Forum, March 30, 2020. Why SubSaharan Africa needs a unique response to COVID-19 | World Economic Forum (weforum.org). Accessed 21 March 2021.

43-Lone SA, Ahmad A. COVID-19 pandemic - an African perspective. Emerg Microbes Infect. 2020;9(1):1300-1308. doi: 10.1080/22221751.2020.1775132.

44- Federal Democratic Republic of Ethiopia Ministry of Health and Ministry of Industry. National strategy and plan of action for pharmaceutical manufacturing development in Ethiopia (2015-2025). WHO I National strategy and plan of action for pharmaceutical manufacturing development in Ethiopia (2015-2025). Accessed 22 February 2021. 
45- Khder SI, Alwakeel A, SaifAldawla A, Ali AA, Kadoma M, Hassan N et al. Measuring availability and prices of locally produced and imported medicines in Sudan. Journal of Medical Informatics and Decision Making 2020;1(2):1-14. doi: 10.14302/issn.26415526.jmid-19-3119

46- Choo EK, Rajkumar SV. Medication shortages during the covid-19 crisis: What we must do. Mayo Clin Proc. 2020;95(6):1112-1115. doi: 10.1016/j.mayocp.2020.04.001.

47- Vorrath J, Voss M. The hidden dangers of falsified and substandard medicines. SWP Comment 2019. The Hidden Dangers of Falsified and Substandard Medicines - SWP (swp-berlin.org). Accessed 12 February 2021.

48- Ayukekbong JA, Ntemgwa M, Atabe AN. The threat of antimicrobial resistance in developing countries: causes and control strategies. Antimicrob Resist Infect Control. 2017;6:47. doi:10.1186/s13756-017-0208-x

49- WHO. COVID-19 significantly impacts health services for noncommunicable diseases. June 2020. COVID-19 significantly impacts health services for noncommunicable diseases (who.int). Accessed 9 March 2021.

50- WHO Regional Office for Africa. COVID-19 hits life-saving health services in Africa. November 2020. COVID-19 hits life-saving health services in Africa | WHO | Regional Office for Africa. Accessed 10 March 2021.

51- Hogan AB, Jewell BL, Sherrard-Smith E, Vesga JF, Watson OJ, Whittaker C et al. Potential impact of the COVID-19 pandemic on HIV, tuberculosis, and malaria in low-income and middle-income countries: a modelling study. Lancet Glob Health 2020; 8: e1132-41. doi: 10.1016/ S2214-109X(20)30288-6

52- Barach P, Fisher SD, Adams MJ, Burstein GR, Brophy PD, Kuo DZ et al. Disruption of healthcare: Will the COVID pandemic worsen non-COVID outcomes and disease outbreaks?. Prog Pediatr Cardiol. 2020;59:101254. doi:10.1016/j.ppedcard.2020.101254

53- Aklilu TM, Abebe W, Worku A, Tadele H, Haile T, Shimelis D et al. The impact of covid-19 on care seeking behavior of patients at tertiary care follow-up clinics: a cross-sectional telephone survey, Addis Ababa, Ethiopia. medRxiv 2020.11.25.20236224; doi: $\underline{10.1101 / 2020.11 .25 .20236224}$

54- Yang J, Gong H, Chen X, Chen Z, Deng X, Qian M et al. Health seeking behaviors of patients with acute respiratory infections during the outbreak of novel coronavirus disease 2019 in Wuhan, China. medRxiv. 2020;2020.05.05.20091553. doi:10.1101/2020.05.05.20091553

55- WHO. COVID-19 Clinical management: living guidance. January 2021. COVID-19 Clinical management: living guidance (who.int) Accessed 28 March 20201.

56-Lynch C, Mahida N, Gray J. Antimicrobial stewardship: a COVID casualty? J Hosp Infect. 2020;106(3):401-403. doi: 10.1016/j.jhin.2020.10.002.

57-Rodríguez-Baño J, Rossolini GM, Schultsz C, Tacconelli E, Murthy S, Ohmagari N et al. Antimicrobial resistance research in a post-pandemic world: Insights on antimicrobial resistance research in the COVID-19 pandemic. J Glob Antimicrob Resist. 2021;25:5-7. doi: 10.1016/j.jgar.2021.02.013.

58- Akpan MR, Isemin NU, Udoh AE, Ashiru-Oredope D. Implementation of antimicrobial stewardship programmes in African countries: a systematic literature review. J Glob Antimicrob Resist. 2020;22:317-324. doi: 10.1016/j.jgar.2020.03.009.

59- Iwu CJ, Jordan P, Jaja IF, Iwu CD, Wiysonge CS. Treatment of COVID-19: implications for antimicrobial resistance in Africa. Pan Afr Med J. 2020;35(Suppl 2):119. doi:10.11604/pamj.supp.2020.35.23713

60- Chukwu EE, Oshun PO, Osuolale KA, Chuka-Ebene VO, Salako A, Idigbe IE et al. Antimicrobial stewardship programmes in healthcare facilities in Lagos state: a needs assessment. J Glob Antimicrob Resist. 2021. ISSN $2213-7165$. https://doi.org/10.1016/j.jgar.2021.02.034.

61- Brodeur A, Gray D, Islam A, Bhuiyan SJ. A literature review of the economics of COVID-19. IZA discussion paper no. 13411. https://ssrn.com/abstract=3636640 Accessed 12 January 2021.

62- International Finance Corporation, World Bank Group. COVID-19 Economic Impact: Sub-Saharan Africa. September 2020. Microsoft Word - Pandemic Response SSA brief 4 Sept 2020 Update.docx (ifc.org) Accessed 25 March 2021.

63-Gondwe G. Assessing the Impact of COVID-19 on Africa's economic development. UNCTAD/ALDC/MISC/2020/3. Assessing the Impact of COVID-19 on Africa's Economic Development (unctad.org). Accessed 16 February 2021.

64- Anna J, Kilic T, Michler JD. Socioeconomic impacts of COVID-19 in four African countries. policy research working paper;no. 9466. World Bank, Washington, DC. https://openknowledge.worldbank.org/handle/10986/34733 Accessed 20 March 2021.

65- United Nations, Ethiopia. Socio-economic impacts of COVID-19 in Ethiopia. Ethiopia Socio-Economic Assessment of the Impact of COVID-19 (reliefweb.int). Accessed 23 February 2021.

66- Hirvonen K. Economic impacts of COVID-19 pandemic in Ethiopia: a review of phone survey evidence. Economic impacts of COVID-19 pandemic in Ethiopia: A review of phone survey evidence (ifpri.org). Accessed 24 February 2021.

67-Rusic D, Vilovic M, Bukic J, Leskur D, Seselja PA, Kumric M et al. Implications of COVID-19 pandemic on the emergence of antimicrobial resistance: adjusting the response to future outbreaks. Life (Basel). 2021;11(3):220. doi: 10.3390/life11030220.

68- Paul D, Mondal SK, Mandal SM. Biologia Futura: use of biocides during COVID-19-global reshuffling of the microbiota. BIOLOGIA FUTURA. 2021. doi: 10.1007/s42977-021-00069-1

69- Chen B, Han J, Dai H, Jia P. Biocide-tolerance and antibiotic-resistance in community environments and risk of direct transfers to humans: unintended consequences of community-wide surface disinfecting during COVID-19?. Environ Pollut. 2021;283:117074. doi:10.1016/j.envpol.2021.117074

70-Kampf G. Biocidal agents used for disinfection can enhance antibiotic resistance in gram-negative species. Antibiotics (Basel). 2018;7(4):110. doi: 10.3390/antibiotics7040110. 
71-Rezasoltani S, Yadegar A, Hatami B, Asadzadeh Aghdaei H, Zali MR. Antimicrobial resistance as a hidden menace lurking behind the COVID-19 outbreak: the global impacts of too much hygiene on AMR. Front Microbiol. 2020;11:590683. doi: 10.3389/fmicb.2020.590683.

72- Achak M, Bakri SA, Chhiti Y, Alaoui MFE, Barka N, Boumya W. SARS-CoV-2 in hospital wastewater during outbreak of COVID19: a review on detection, survival and disinfection technologies. Sci Total Environ. 2021;761: 143192. doi:10.1016/j.scitotenv.2020.143192

73- Murray AK. The novel coronavirus COVID-19 outbreak: global implications for antimicrobial resistance. Front Microbiol. 2020;11:1020. doi:10.3389/fmicb.2020.01020

74- Egyir B, Obeng-Nkrumah N, Kyei GB. COVID-19 pandemic and antimicrobial resistance: another call to strengthen laboratory diagnostic capacity in Africa. Afr J Lab Med. 2020;9(1):1302. doi: 10.4102/ajlm.v9i1.1302.

75- Strathdee SA, Davies SC, Marcelin JR. Confronting antimicrobial resistance beyond the COVID-19 pandemic and the 2020 US election. Lancet. 2020;396(10257):1050-1053. doi: 10.1016/S0140-6736(20)32063-8. 